\title{
Intersubjetividad, memoria y reconocimiento. Perspectivas interculturales de la ética y del medioambiente
}

\section{Intersubjetividade, memória e reconhecimento. Perspectivas interculturais da ética e do meio ambiente}

\section{Intersubjectivity, Memory and Recognition. Intercultural Perspectives of Ethics and the Environment}

\author{
Ricardo SALAS Astrain*
}

\begin{abstract}
RESUMEN
En este trabajo, queremos profundizar algunos resultados de una perspectiva intercultural del medio ambiente en el marco de una historia de la negación de las visiones y prácticas que tienen las comunidades de vida. Centraremos el tema del medio ambiente y de la ética a partir de algunos temas derivados de la filosofía de Levinas. Nuestra hipótesis se inspira en la idea levinasiana de que es menester asumir con fuerzas la idea de la distancia y de la imposibilidad de la globalidad de uno por el otro, o de un camino de la mera correspondencia, por el ideal de la absolutez del otro, lo que implica que en el análisis del territorio y de los problemas ambientales es preciso reconocer la implantación de modelos dominantes de un modelo económico hegemónico que no dejan siempre cabida para asumir otras subjetividades que no se mueven por el poder, por el lucro o simplemente por la acción estratégica. Este nuevo modo de encarar el análisis intercultural del territorio nos parece que es fecundo ya que demuestra el modo como las categorías levinasianas del Otro facilitan repensar una fenomenología de lo interhumano, y que refiere a la resistencia de los seres humanos y de las culturas frente al predominio de lo Mismo.
\end{abstract}

Palabras clave: reconocimiento; alteridad; medio ambiente.

\section{RESUMO}

Neste texto, queremos aprofundar alguns resultados desde uma perspectiva intercultural do meio ambiente, no âmbito de uma história da negação das visões e práticas pertencentes às comunidades de vida. Focaremos o tema do meio ambiente e da ética a partir de alguns aspectos derivados da filosofia de Levinas. Nossa hipótese se inspira na ideia levinasiana de que é necessário assumir resolutamente a ideia da distância e da impossibilidade da globalidade de um pelo outro, ou de um caminho da simples correspondência, pelo ideal do absolutismo do outro, o que implica que na análise do território e dos

\footnotetext{
"Doutor em Filosofia, profesor da Facultad de Ciencias Sociales de la UC de Temuco, Chile. Email: rsalas@uct.cl
} 
problemas ambientais é necessário reconhecer que a implantação de um modelo econômico hegemônico impede a emergência de outras subjetividades desinteressadas pelo poder, pelo lucro ou simplesmente pela ação estratégica. Este novo modo de enfrentar a análise intercultural do território nos parece que é fecundo, uma vez que demonstra que o uso das categorias levinasianas do Outro facilita repensar uma fenomenologia do inter-humano, relativa à resistência dos seres humanos e das culturas em oposição ao predomínio do Mesmo.

Palavras-chave: reconhecimento; alteridade; meio ambiente.

\begin{abstract}
In this paper, we want to explore some results of an intercultural perspective of the environment in the context of a history of denial of visions and practices of the living communities. We will focus the topics of environment and ethics resulting from some themes derived from Levinas' philosophy. Our hypothesis is based on the Levinasian idea that force is necessary to assume the idea of distance and the impossibility of the totality from one to another, or a way of mere correspondence, for the ideal of the absoluteness of the other. This idea implicates that the analysis of territory and environmental problems requires recognition of the establishment of dominant models of a hegemonic economic model that does not always leave place to assume other subjectivities that do not move for power, for profit or simply by strategic action. This new manner of dealing with the intercultural analysis of territory seems to be fecund, since it shows how Levinas' categories of the 'other' facilitate the rethinking of a phenomenology of the interpersonal, and refers to the resistance of human beings and cultures towards the predominance of the same.
\end{abstract}

Key-words: recognition; otherness; environment.

\section{Introducción}

En una perspectiva intercultural acerca de las relaciones con los otros en América Latina asume como tarea el comprender, teórica y prácticamente, una larga historia de conflictos identitarios y de a-simetrías del encuentro-desencuentro de los seres humanos y de comunidades de vida en territorios latinoamericanos, por la cual se nos ha hecho habitual el uso de la categoría de "lógica de negación” según la conocida terminología de R. Kusch. En efecto, un trazo común de la historia de nuestros países son sus prácticas históricas homogenizadoras, esto es así tanto al considerar la acción colonizadora de los imperios y de las actuales metrópolis y luego la acción de los estados latinoamericanos donde los estados asumieron como proyecto estratégico la implantación de modelos que eran relevantes para los intereses estratégicos de las grandes centros urbanos.

En este trabajo, queremos profundizar estos resultados de esta historia de la negación, pero queremos centrarlos ahora aplicados al tema del medio ambiente y de la ética a partir de algunos temas derivados de la filosofía de Levi- nas. La óptica no es tanto indagar y profundizar el planteo filosófico - de tipo fenoménico-ontológico acerca de lo humano e interhumano -, sino destacar que en el análisis del territorio es preciso considerar de un modo más radical algunos supuestos que conllevan estas conflictivas luchas de reconocimiento y de las memorias de negación de las comunidades humanas, y en especial de los pueblos indígenas. En esto seguimos la pista de los filósofos interculturales que han asumido esta empresa de pensar lo interhumano, en especial me refiero a las obra de filósofos como R. Fornet-Betancourt y A. Sidekum.

Nuestras hipótesis se inspira en la idea levinasiana de que es menester asumir con fuerzas la idea de la distancia y de la imposibilidad de la globalidad de uno por el otro, o de un camino de la mera correspondencia, por el ideal de la absolutez del otro, lo que implica que en el análisis del territorio y de los problemas ambientales es preciso reconocer la implantación de modelos dominantes que no dejan siempre cabida para asumir otras subjetividades que no se mueven por el poder, por el lucro o simplemente por la acción estratégica. Este nuevo modo de encarar el análisis intercultural del territorio nos parece que es fecundo ya que 
demuestra el modo como las categorías levinasianas del Otro facilitan repensar una fenomenología de lo interhumano, y que refiere a la resistencia de los seres humanos y de las culturas frente al predominio de lo Mismo.

Con estas ideas la relación intersubjetiva no solo se vuelve central, ya que solo podemos avanzar mucho más allá de la apertura de un sujeto a algo que lo trasciende cuando alcanzamos la posibilidad de abrirnos a un tercero. En otras palabras, es la instauración del entre-nosotros el que nos permite redefinir de otro modo el cruce de la cuestión de la intersubjetividad y del reconocimiento justo en algunos textos levinasianos que expondremos en la primera parte de este artículo ${ }^{1}$. En un artículo preparatorio de su obra cumbre Totalidad e infinito, ¿Es fundamental la ontología? del año 1951 decía Levinas acerca de la relevancia del para-otro: "Se investiga la racionalidad del psiquismo humano en la relación intersubjetiva, en la relación de unos con otros, en la trascendencia del 'para-otro', que instaura el sujeto ético, que instaura el 'entre-nosotros"” (LEVINAS, 2001, p. 9). La obra de Levinas como se sabe impacta fuertemente entre muchos pensadores, sobre todo queda de manifiesto la incorporación de sus terminologías en la discusión con la filosofía latinoamericana de los años 70-90, que ya ha sido estudiada en otros textos, aquí solo relevaremos como estas nociones contribuyen a elaborar una perspectiva crítica de los contextos culturales asimétricos, en la que podamos desarrollar algunos aspectos de esta tesis acerca de la imposibilidad de la asimilación homogenizante del otro. En una primera parte del artículo nos inspiraremos en la discusión de la filosofía intercultural para hablar de la sociedad del conocer, luego mostraremos algunos tópicos de la filosofía levinasiana y para finalizar, destacaremos unos temas conclusivos que aluden acerca del reconocimiento y de la reconstrucción de las identidades en nuestras conflictivas relaciones a la memoria.

\section{La problemática contextual de la sociedad del conocer}

Frecuentemente la sociedad del conocimiento se la ha analizado desde los contextos de producción científico-técnico de las grandes economías, y no se la observa el modo como ella va asociada a las tensiones y contradicciones de nuestros modos homogéneos y homogenizantes de pensar y practicar la ciencia y la tecnología en nuestros países. En muchos de nosotros, se la reconoce solo como ella se ha producido occidentalmente, pero no se analiza las circunstancias particulares del papel de tal sociedad en países que vivimos en los márgenes de occidente, y que somos parte de un occidente periférico.

Para los colegas que trabajamos en el marco de un pensar intercultural el ensayar de definir una óptica crítica del conocimiento es una exigencia central de este tiempo de crisis de las ciencias y del proyecto que ella ha definido para todas las sociedades. Así el cuestionamiento de lo que contemporáneamente se denomina "la sociedad del conocimiento" es capital porque exige desplegar otra discusión acerca de los modos contextuales de asumir tal tipo de sociedad y también de lo que llama la tecnociencia -que es parte de un desarrollo científico y tecnológico definido notoriamente por los grandes países que iniciaran esta carrera de la ciencia-técnica como motor de sus economías. Al realizar esta crítica de la hegemonía tecnocientífica no se quiere defender la idea de una sociedad pueda hoy marginarse de estos procesos, sino simplemente demostrar la ingenuidad de algunos planteamientos gubernamentales y entender que una nueva discusión ampliada acerca de la relevancia de la ciencia en nuestro tiempo exige asumir, lo que llamaría en general, como filósofo, los "saberes humanos", y no únicamente los conocimientos de las empresas interesadas en hacer crecer sus negocios.

Tal discusión ha sido acrecentada en la filosofía intercultural y en las ciencias sociales críticas actuales, porque la ciencia y la técnica predefinen una ontología formalizante que ha diluido otros accesos a lo real, y ha subsumido en el modelo empírico-formal otros modelos de acercamiento a la realidad social y humana, que aparece permanentemente resguardado por las comunidades indígenas y de pequeños productores. Nos parece que hoy existe una preocupación mayor por dar cuenta con una mirada plural de la sociedad hegemónica del conocimiento, nos permite entender como ella ha ocultado en la mayor parte de nuestros países una desvalorización de los saberes humanos que no responden siempre a la forma predominante del conocimiento científico, y que oculta una profunda desvalorización de los seres

\footnotetext{
${ }^{1}$ La temática de este artículo es parte del proyecto Fondecyt1090153: "Intersubjetividad y reconocimiento en la filosofía contemporánea. Lecturas sobre el legado de Husserl en la fenomenología francesa (Merleau Ponty, Levinas, Ricoeur y Ladriére)”.
} 
y comunidades humanas que no tienen una relación con el territorio y el medio ambiente en términos de cálculo.

Estas ideas iniciales que son muy generales parten de la base de que una noción de "sociedad del conocimiento" oculta una prenoción no suficientemente develada, de que existe algún conocimiento privilegiado, y lo que un pensar intercultural quiere destacar principalmente es que no existe un solo tipo de conocimiento acerca del mundo, y que llevando la cuestión a su nivel de mayor complejidad ontológica, que existen en todas las sociedades históricas diferentes mundos y saberes que se despliegan en las redes simbólico-intelectuales que viven todas las sociedades humanas. En otras palabras, lo que conocemos es siempre parte de un conjunto de saberes que se despliegan siguiendo parámetros definidos por los contextos culturales, donde etnográfica e históricamente podemos reconocer varios tipos de conocimientos.

Una sociedad denominada tradicional por la sociología, contiene muchos más formas sociales con diversos conocimientos y saberes, que lo que ha reconocido inicialmente las teorías históricas y etnológicas del siglo XIX en casi todos nuestros países. En todas las sociedades indígenas en América por ejemplo, si consideramos los aportes dejados por Paul Radin para Norteamérica, Leon-Portilla para el mundo nahua, Cadogan y Melìa para el mundo guaraní, Kusch para el mundo quechua, etc había en todas ellas una clara y decidida valorización del conocimiento, había y hay en las lenguas indígenas que se hablan actualmente en Indoamérica, varias expresiones específicas para decir saber, conocer, reflexionar, aprender, enseñar, etc, de modo que si somos justos cabría decir que las nociones de "hombre sabio" o del "hombre que tiene conocimiento" que forman parte del patrimonio de nuestras sociedades actuales, son parte de una larguísima tradición cultural de la humanidad que cabría analizar endógenamente, estas nociones no son un invento griego ni tampoco es algo que trae la cultura europeo-occidental a tierras indígenas.

Aunque algunos lo consideren todavía como mero exotismo, es preciso reconocer estos mundos étnicos de vida que configuraron los primeros mundos de estas tierras. Habían tribus, nos dicen los estudiosos, que tenían técnicas que llamaríamos hoy muy simples, pero que en sus lenguas tenían nociones tan específicas para definir lo que hoy llamaríamos un filósofo, un teólogo, un astrónomo, un médico, un lingüista. En estas sofisticadas lenguas indígenas, que hablaban personas que vivían con una escasa sofisticación científico-técnica, habían llegado a la elaboración de miles de palabras en lenguajes tan ricos como sofisticadísimos para dar cuenta del entorno natural que les rodeaba, de modo que los primeros europeos que examinaron dichas lenguas, misioneros-lingüistas u otros se maravillaban de lenguas de un nivel de perfección, que harían palidecer a los locutores de las sociedades mestizas que se reducen a unos pocos miles de palabras, y a un empobrecimiento de los saberes y del mundo. Este es un llamado de atención a criticar modelos de interpretación que marcado fuertemente la formación escolar y universitaria que no responden más a una parcelación de lo que efectivamente en dichas sociedades había de la sociedad humana.

La tesis que subyace a esta constatación no es nueva, es volver a considerar que la llamada sociedad moderna surge inicialmente por este gesto definitorio del Ego Cogito de Descartes y de la realidad como un libro de caracteres matemáticos según Galileo que aseguraron el predominio de un conocer de tipo universal y apodíctico que por lo general es simplemente una reducción formalizadora que aseguró el desarrollo de las ciencias formales, como la lógica y la matemática. Es solamente por un prejuicio histórico de la humanidad europea acerca de la ciencia moderna, que se definió un prototipo de conocimiento "universal" en desmedro de otros que fueron considerados "particulares". Frente al conocimiento de la mathesis universales se opuso el saber común. Es notable que este prejuicio haya debido esperar hasta la elaboración más lúcida del Padre de la fenomenología alemana, E. Husserl para que pudiera ser visibilizado filosóficamente. En su famoso libro de la Crisis de las Ciencias Europea, Husserl lo considera como parte del error de la ratio moderna, empero no es sólo el mundo germano que descubre este empobrecimiento del mundo, ya que tendríamos que considerar que muchos sabios indígenas habían cuestionado este modo de empobrecer lo real. Cabría junto a la Crisis husserliana, agregar los aspectos desarrolados por "una geocultura del saber" al modo de R. Kusch, quien invitó a criticar las limitadas formas de esconder el saber arraigado en el pensamiento indígena y popular, acunado por los llamados descubridores, colonizadores, civilizadores de América.

La cuestión de la "colonialidad del saber" que ha entrado fuertemente en el debate de estos últimos años apunta a este denodado esfuerzo epistémico de esos grandes Imperios empeñados en desconocer y desvalorizar los saberes, los mundos de vida y las eticidades propias de las culturas humanas. Esto me parece que no es algo vivido y sufrido solo por Indoamérica, sino que es parte de la larga 
historia de la humanidad, donde el saber y el poder han confluido en proyectos de dominación, de subordinación y de imposición de unos conocimientos sobre otros, se trata siempre de una lucha de saberes. Saberes instrumentales y de eficacia militar versus saberes humanos que permiten vivir la vida de otro modo más humano. El camino proseguido por esta humanidad plural es que ella no ha aprendido aún a reconocer la complejidad del saber humano, con muchas dificultades reconoce los saberes pre-existentes en todos esos territorios cartografiados por los imperios a escala planetaria, y nos impide considerar la complejidad misma del conocer humano que responde primeramente por las vicisitudes de mundos humanos.

\section{Levinas y la herencia de la fenomenología}

En este trabajo solo destacaremos la figura descollante de E. Levinas, quien desde mucho antes de la publicación de Totalidad e infinito (1961) ya destacaba un conjunto de categorías filosóficas acerca de la subjetividad, del tiempo, del rostro, y del otro que marcaron todo este debate, y dejaremos el análisis de los otros filósofos para posteriores trabajos. El marco fenomenológico general de E. Levinas acerca de la alteridad y del otro parte de una crítica de la noción de Ego del cartesianismo y que se manifiesta también las ideas husserlianas y heideggerianas acerca de la intersubjetividad.

Respecto de la teoría de Husserl retoma el desarrollo planteado en la Meditaciones Cartesianas - del que fue su primer traductor francés -, pero cuestiona que el otro se defina desde la estructura de la conciencia (lo mismo), y en el caso de Heidegger cuestiona la idea de coexistencia pero que reposa igualmente "en la relación del ser en general, en la comprensión, en la ontología" (LEVINAS, 1977, p. 91). En ambos casos, se valora los desarrollos fenomenológicos avanzados en lo noético y en lo ontológico, pero se les cuestiona la falta de una radicalidad mayor, se podría decir que se trata de valorizar que la relación con el otro se da más allá del conocimiento objetivo, pero destaca que es preciso entenderla bajo el modo de la revelación. Esta radicalidad de la fenomenología de Levinas es un avance particular frente al planteo del otro. Aunque sus dos maestros alemanes sigan siendo decisivos en el plantea, de los dos discrepa de su noción de yo, de análisis inmanente de la conciencia y de ser en el mundo. En esto Levinas, prolonga y proyecta la fenomenología con un cuestionamiento radical de la otredad.
En primer lugar es preciso indicar que el análisis filosófico consagrado por Levinas a partir de su libro $T_{0}$ talidad e infinito (1961) y que lleva por subtítulo justamente "Ensayo sobre la exterioridad", retoma una parte importante de sus anteriores interpretaciones de Husserl y Heidegger de los años 50 (lo que se expresa en obras tales como $L a$ théorie de l'intuition dans la phénoménologie de Husserl, 1930, y De l'existence á l'existant, 1947, y En Découvrant l'existence avec Husserl et Heidegger, 1949). Aquí se resume lo esencial del ser entendido como exterioridad: "Plantear el ser como exterioridad, es percibir lo infinito como el Deseo de lo infinito, y por ello, comprender que la producción de lo infinito invoca la separación, la producción de la arbitrariedad absoluta del yo o del origen" (LEVINAS, 1977, p. 296).

En segundo lugar, este libro que es uno de los textos mayores del tema de la Otredad en el siglo XX no es un libro de juventud, sino de plena madurez, junto a manifestar la gratitud hacia sus maestros inspiradores, Levinas no trepida en radicalizar sus planteos, pero donde la crítica desde el inicio levanta el talante propiamente ético del camino propiamente ético elaborado por Levinas. Dicho en sus propias palabras: "[...] pero el ser-para-el-otro no es una relación entre conceptos cuya comprensión coincidiría, ni la concepción de un concepto para un yo, sino mi bondad. El hecho de que, existente para el otro, existo de otro modo que al existir para mi, es la moralidad misma" (LEVINAS, 1977, p. 271).

En este interés nuestro de develar el sentido de la intersubjetividad la idea de fondo del libro Totalidad e Infinito es crucial ya que ella refiere a una cuestión central debatida en el marco de la filosofía existencial del siglo XX acerca del estatuto del ser humano como ente abierto a los otros. Tal como lo enuncia el mismo Levinas: "Se deben a la coyuntura Yo-Otro, a la orientación inevitable del ser 'a partir de sí' hacia 'el Otro"” (LEVINAS, 1977, p. 228). Siguiendo las enseñanzas de la filosofía cartesiana, Totalidad e infinito retoma la idea del infinito considera que esta idea de Descartes sigue de algún modo el esquema neoplatónico del retorno a la unión preconizada por el neoplatonismo, y marcará el destino del filosofar moderno. Levinas decide asumir la categoría de infinito como central para replantearla de una manera tal que el yo asuma su deuda con la exterioridad.

En otros términos, Levinas postula que este pensar definido por Descartes terminará definiendo el pensamiento moderno, asumido por el pensar hegeliano en los temas 
del retorno a sí del pensamiento absoluto, la identidad de lo idéntico y lo no idéntico en la conciencia de sí, pero también en el pensar husserliano donde se termina considerando finalmente "toda trascendencia, toda alteridad, toda exterioridad queda reducida o reconducida a la inmanencia de una subjetividad que se exterioriza a si misma y en si misma» (LEVINAS, 2001, p. 167). En otras palabras, la tesis levinasiana elaborada en contra de esa modernidad marcada por el infinito cartesiano, es que intenta cuestionar una idea de la unidad filosófica de lo real a partir de la estructura de la conciencia cerrada, para considerarla en un vínculo exterioridad que la precede, a la que se debe.

Estas ideas postulan un nuevo tipo de análisis eidético que desafía además el pensar de lo trascendente de la filosofía de la modernidad siguiendo la idea de que "Lo trascendente es aquello que no podría ser englobado" (LEVINAS, 1977, p. 297) e implican una revisión de la idea de logos filosófico y su vínculo con la religión. Este modo diferente de acceder a lo trascendente es ciertamente algo que no depende solo del patrimonio griego, sino que recupera la tradición hebrea del Talmud, y en esto la propia inspiración de Levinas está abierta a una trascendencia religioso-cultural. Empero, en el terreno propiamente filosófico, estas críticas racionales a la idea de infinito de Descartes, luego reelaboradas por Hegel y Husserl son parte del marco de la crítica a la ontología moderna que es preciso reinventar de otro modo si se quiere comprender un ente que no se puede definir por lo Mismo, sino que es plena apertura a una realidad que la excede y del que él es prenda. "La primera persona del presente, en el Cogito, merced al cual Hegel o Husserl se reconocen en el terreno de la filosofía moderna, garantiza al saber su unificación congénita y su autosuficiencia, que prefiguran la unidad sistemática de la conciencia y la integración de todo lo que sea otro en el sistema y en el presente o en la sincronía - intemporal - del sistema" (LEVINAS, 2001, p. 167).

Este cuestionamiento del mito de la modernidad bajo la fórmula del Ego cogito, yo moderno no sólo refiere a Hegel y Husserl, sino al mismo intento elaborado por Heidegger de preservar la autenticidad del Dasein (LEVINAS, 2001, p. 274) como asimismo la idea de comprender el sentido mismo del Ser. No se ha dicho suficientemente que la separación con el pensar de Heidegger ya se hizo notar en sus trabajos de los años 40: "El Yo es la crisis misma del ser y del ente en lo humano. Crisis del ser, no porque el sentido de este verbo tuviera que comprenderse aún en su secreto semántico, apelando así a la ontología, sino porque yo me pregunto de entrada si mi ser está justificado, si el Da de mi Dasein no es ya usurpación del lugar del otro" (LEVINAS, 2001, p. 177).

Situadas así las críticas a sus dos maestros alemanes de la fenomenología, la cuestión no es cuestionar toda idea de la subjetividad moderna, sino de mostrar sus límites y su fragilidad para dar cuenta de algo que no es ella. En el prefacio a la edición francesa Levinas señala que en relación a la valorización temática de la subjetividad se da inevitablemente en la apertura a un otro, donde se resuelven las ideas de hospitalidad e infinito. Un poco más arriba desglosa esta misma idea cuando señala de un modo explícito: "Este libro se presenta entonces como una defensa de la subjetividad, pero no la tomará al nivel de su protesta puramente egoísta contra la totalidad, no en su angustia ante la muerte, sino como fundador de la idea de infinito $[\ldots]$ presentará la subjetividad, recibiendo al otro, como hospitalidad. En ella se lleva a cabo la idea de infinito" (LEVINAS, 2001, p. 52). Este mismo énfasis lo encontramos en el prefacio a la edición alemana, Levinas explaya esta idea considerando que el espíritu general de Totalidad e infinito está definido por el cuestionamiento de la síntesis del saber, "la totalidad del ser abarcado por el yo trascendental, la presencia aprendida en la representación y en el concepto, y la interrogación sobre la semántica de la forma verbal del ser no pueden ser la instancia última del sentido [...] más allá del en-si y del para-si de lo desvelado está la desnudez del hombre, más exterior que el afuera del mundo" (LEVINAS, 2001, p. 266).

Estos desarrollos se ven reflejados en la estructura formal de este libro ya que éste trasunta, entonces según el traductor D. Guillot de la obra al castellano, en la idea de una refundación de la alteridad que brotaría necesariamente de la crítica de la idea de infinito cuyo contenido consiste en sobrepasar permanentemente todo contenido y por la cual se contiene más de lo que se puede contener. Esta crítica levinasiana de idea límite de la filosofía cartesiana es relevante, ya que permite superar la duda de la subjetividad dando cuenta de la experiencia del cara a cara en el plano conceptual. El otro sería en esta primera aproximación, precisamente lo que no se puede neutralizar en un contenido conceptual ya que el concepto lo pondría a mi disposición y sufriría así la violencia de la conversión del Otro en lo Mismo. La idea de lo infinito expresa esta imposibilidad de encontrar un término intermedio - un concepto - que pueda amortiguar la alteridad del Otro. El Otro como lo absoluto es una trascendencia anterior a toda razón y a lo universal, 
porque es precisamente, la fuente de toda racionalidad y de toda universalidad. Cf. Guillot, D. Introducción castellana a Totalidad e infinito, p. 25). Veamos más precisamente lo que conlleva esta idea del Otro en la teoría de Levinas.

\section{El otro levinasiano}

Considerar de un modo más preciso la cuestión de la categoría de lo Mismo a la que se hace alusión, implica definirlo como absolutamente diferente del Otro, implica también no proponer una idea simple de la identidad del yo y de que lo exterior, es decir de aquello que le excede y precede, no se define nunca desde la propia subjetividad. Para Levinas, se trata de mostrar que la relación del Yo se juega permanente en su propia identificación, de modo que el yo frecuentemente está prisionero de Lo Mismo, y no puede alcanzar desde esta estructura egoica, sino algo meramente horizontal, a un otro yo contingente, que no le es absolutamente diferente, sino que es parte de una relación horizontal: "Si el Mismo se identificase por simple oposición a lo Otro, formaría ya parte de una totalidad que englobaría lo Mismo y lo Otro" (LEVINAS, 1977, p. 62).

Aquí se vuelve relevante la idea del infinito, ya que el otro es justamente aquello que no puede ser homogenizado por el yo e instala un nuevo modo de entender el reconocimiento humano que es plenamente ético que permite romper con el predominio de la epistemología: "Al plantear la relación como ética, se sobrepasa una dificultad que sería inevitable si la filosofía, contrariamente a Descartes, partiese de un cogito planteado de modo absolutamente independiente del otro" (LEVINAS, 1977, p. 224). Nos dice también explícitamente: "El otro no puede ser contenido por mí, cualquiera que sea la extensión de mis pensamientos, de este modo ilimitado: es impensable, es infinito y reconocido como tal. Este reconocimiento no se produce de nuevo como pensamiento, sino como moralidad" (LEVINAS, 1977, p. 244).

Sin embargo, y esta es la paradoja más interesante de una obra de un hombre que vivió en su propia vida y en la de su comunidad hebrea, el triunfo de la destrucción de los otros inocentes en la segunda gran guerra del siglo pasado, donde los enemigos no eran soldados, sino todos aquellos que no tenían humanidad frente a la máquina de destrucción: niños, jóvenes y viejos eran lo mismo, mujeres y hombres eran solo la materia de algo que no les asignaba vida, era materia desechable, por ello se vuelve central la bella expresión del rostro como característico de lo humano. "La verdadera esencia del hombre se presenta en su rostro, en el que es infinitamente y no una violencia parecida a la mía, opuesta a la mía y hostil y ya en conflicto con la mía en un mundo histórico en el que participamos en el mismo sistema" (LEVINAS, 1977, p. 295). Para Levinas, se trata así no de encontrar un punto de medida entre el yo y el otro, sino más bien de encontrar una distancia abisal donde el otro no es nunca reducible, al menos si lo situamos en el terreno de una ética interhumana, "una relación cuyos términos no forman una totalidad, solo puede producirse, pues en la economía general del ser como tránsito del Yo al Otro, como cara a cara, como perfilando una distancia en profundidad - la del discurso, de la bondad, del Deseo - irreductible a aquello que la actividad sintética del entendimiento establece entre los términos diversos -mutuamente - que se ofrecen a esta operación psicológica" (LEVINAS, 1977, p. 63)

Por ello no se dirá bastante que la categoría del rostro es fenomenológica, es decir que no refiere a características antropocentricas de una faz concreta, de color etc, sino que se trata de una categoría que quiere mostrar que en lenguaje eminentemente filosófico, la ética apela a algo que es lo propio y específico del ser humano que se nos revela y que no es manipulable: "Lo que llamamos rostro es precisamente esa presentación excepcional, presentación de sí por sí mismo, sin medida común con la presentación de realidades simplemente dadas [...]" (LEVINAS, 1977, p. 216).

En Totalidad e infinito, encontramos desarrollos notables de como se da esa relación entre el yo y el otro, pero sin desmerecer la riqueza genuina de esos encuentros, aparece uno decisivamente humano: Para Levinas existen diversas formas que asume esta relación no englobante, para él la relación por excelencia entre el Yo y el otro se juega en el lenguaje: "La relación del Mismo y del Otro - o metafísicafunciona originalmente como discurso, en el que el Mismo, resumido en su ipseidad de 'yo' - de ente particular único y autóctono- sale de sí” (LEVINAS, 1977, p. 63).

\section{La ética levinasiana y la idea de responsabilidad frente al otro}

En todo lo dicho hasta aquí, aparece una crítica radical a la subjetividad moderna definida por el Ego Cogito, y esta crítica permite definir una vía de acercamiento y sobre todo de la obligación que tengo frente a los otros: "La superación 
de la existencia fenomenal o interior, no consiste en recibir el reconocimiento del otro, sino en ofrecerle su ser. Ser en sí es expresarse, es decir, servir ya al otro. El fondo de la expresión es la bondad" (LEVINAS, 1977, p. 200). En el importante artículo El Yo y la Totalidad, 195, sostiene explícitamente Levinas que la idea del reconocimiento es central en esta filosofía: "Esta existencia tributaria del reconocimiento por parte del otro, se torna insignificante cuando carece de él, se percibe como una realidad sin realidad, se convierte en puramente fenoménica" (LEVINAS, 2001, p. 38). En otras palabras, los hombres y mujeres fenoménicos, son aquellos y aquellas que dejan de interpelar con sus rostros, y esto es esencial en tipo de historia de facticidad donde los hombres y mujeres terminan siendo solo instrumentos de las relaciones de los que dominan, de los que tienen el poder, de los que no reconocen a los otros, sino solamente a los mismos que gozan del mantenimiento del sistema. Nos dice Levinas: "La verdadera esencia del hombre se presenta en su rostro, en el que es infinitamente y no una violencia parecida a la mía y hostil y ya en conflicto con la mía en un mundo histórico en el que participamos en el mismo sistema" (LEVINAS, 1977, p. 295).

Empero el reconocimiento y la reciprocidad que le es consustancial se vuelven dramáticas en el mundo histórico real de los hombres, es así como sobre todo en la vida política donde se expresa la historia de las relaciones de no reciprocidad. Nos dice al terminar Totalidad e infinito: "Humanidad de hombres intercambiables, de relaciones recíprocas. La sustitución mutua de los hombres, falta de respeto original, hace posible la explotación misma...la justicia consiste en hace de nuevo posible la expresión en la que, en la no-reciprocidad, la persona se presenta como única. La justicia es derecho a la palabra" (LEVINAS, 1977, p. 302). En otras palabras, la justicia se presenta como el ideal ético de que no se puede entender el mundo histórico desde la facticidad del poder: "Toda relación social, como derivada, se remonta a la presentación del Otro al Mismo, sin ningún intermediario, imagen o signo, por la sola expresión del rostro" (LEVINAS, 1977, p. 277)

Esta idea muestra que para Levinas la historia humana no tiene un guion que defina todas las relaciones, hay una imposibilidad de hacer una totalización de todos los yo, lo que demuestra que no es posible saber en esa historia humana quien maneja esa caótica multiplicidad de yoes, sino encontrar aquello que le permita dar sentido ético: "Pero un principio atraviesa todo este vértigo y todo este temblor, cuando el rostro se presenta y reclama justicia" (LEVINAS,
1977, p. 298). El tiempo y la historia no son conducidos, ellos son siempre eventos que irrumpen y nos sorprenden como acontecimientos: "Lo esencial del tiempo consiste en ser un drama, una multiplicidad de actos donde el acto siguiente desata el primero. El ser no se produce ya de un solo golpe, irremisiblemente presente. La realidad es lo que es, pero será una vez más, otra vez libremente recobrada y perdonada" (LEVINAS, 1977, p. 291).

Nos parece que la idea de reconocimiento definida por Levinas conlleva afirmar con fuerzas al mismo tiempo la idea de la justicia. La cuestión de la justicia es justamente la medida concreta de la reciprocidad y la única que permite afirmar la vida humana mas allá de las astucias del poder: "Es así porque la injusticia - reconocimiento y, a la vez, desconocimiento - es posible gracias al otro que fuerza y tienta como instrumento de la astucia" (LEVINAS, 2001, p. 43). En este ejercicio del reconocimiento, se encuentra el valor del lenguaje como instancia que permite esa relación de reciprocidad. Hablando del interlocutor: "Le reconozco, es decir, creo en él. Pero si este reconocimiento fuese mi sumisión a él, esa misma sumisión retiraría todo valor a mi reconocimiento: el reconocimiento por la sumisión anularía mi dignidad, que es lo que dota de valor al reconocimiento" (LEVINAS, 2001, p. 48). Aquí aparece el valor pleno del mandato: "Pero somos nosotros cuando nos damos un mandamiento, gracias al cual precisamente nos reconocemos" (LEVINAS, 2001, p 49).

Pero estas ideas del reconocimiento suponen un desmontaje completo de la vieja teoría hegeliana del reconocimiento, la lectura genial que hace Levinas de esta concepción es que más de lo mismo, sin apertura a ninguna exterioridad: "La relación con el Otro - absolutamente otro - que no tiene fronteras con el Mismo, no se expone a la alergia que aflije al Mismo en una totalidad y sobre la que reposa la dialéctica hegeliana" (LEVINAS, 1977, p. 216217). En definitiva, lo que se vuelve relevante aquí, es que la tradición de la lucha no logra trascenderse a sí misma:

Si la resistencia al asesinato no fuese ética sino real, tendríamos de ella una percepción con todo lo que en la percepción se vuelve subjetivo. Permaneceríamos en el idealismo de una conciencia de la lucha y no en relación con el Otro, relación que puede convertirse en lucha, pero desborda ya la conciencia de la lucha. La epifanía del rostro es ética. La lucha con la que este rostro puede amenazar presupone la trascendencia de la expresión (LEVINAS, 1977, p. 213). 
Son justamente estas ideas las que nos parecen que tienen vinculaciones directas con la crisis ambiental y con los nuevos desarrollos de la ecología.

\section{Sociedad del conocimiento y medio ambiente}

La primera cuestión que habría que plantearse es la relación que tiene el pensamiento de Levinas con el pensamiento ambiental latinoamericano. Se podría indicar siguiendo a G. Kerber que "La crisis ambiental y la ecología latinoamericana plantean no sólo cuestionamientos o desafíos. También muestran un camino práctico que hace su aporte a la filosofía”. En este sentido, los planteos de Levinas pueden entrar en diálogo entre la ecología latinoamericana, la ecología social y la ecología profunda del Norte. Para hace este diálogo es menester sobrepasar las dificultades que plantea una teoría filosófica para los no iniciados: en filosofía las terminologías levinasianas no las podemos entender sin el esfuerzo llevado a cabo por la filosofía contemporánea por desmontar la idea de la racionalidad moderna y esto que hemos llamado en la primera parte el sujeto. La crisis en la que vivimos hoy no es solo una crisis de un modo económico de producción que no es sustentable, sino que se enraíza en un tipo de filosofía racionalista que presupone la primacía del sujeto, y cuestiona seriamente las posibilidades de proponer una relación intersubjetiva, no solo con los otros sino también con el entorno social y la naturaleza. Al desconocer las bases de una relación alterativa, la intersubjetividad se vuelve un tema crucial como lo deja de manifiesto el pensar de E. Huuserl.

En este sentido el pensamiento de Levinas se vuelve clave para repensar la relación con el otro/s, pero también el modo como el sujeto es parte de un lazo intersubjetivo que cuestiona la gnoseología que está a su base. Como indica Leff: "La problemática ambiental aparece como una crítica de una racionalidad económica prevaleciente y a los estilos de desarrollo dominantes; de esta forma implica el cuestionamiento del conocimiento que se ha venido produciendo y legitimando en ese proceso histórico" (LEFF, 1994, p. 14). Las ideas levinasianas se pueden hacer mucho más amigables al público ambientalista, si extendemos la cuestión del medio ambiente y de la ecología a una crítica no solo al campo tecno-científico de comprender e intervenir los territorios, sino de un modo de comprender las ciencias en la modernidad. En nuestros países, gracias al modo de insertarlo el positivismo decimonónico en las instituciones educativas, sigue la ciencia gozando de un prestigio sin igual entre el grueso público y resulta algo parecido en el análisis de la tecnología, al parecer existe un velo de ignorancia acerca de la crítica de la subjetividad moderna, un manto que impide develar las consabidas dificultades que contiene el conocimiento cientificista moderno y sus derivaciones tecnológicas para responder a los desafíos crecientes del cuidado del medio ambiente para los que vivimos hoy inmersos en esos procesos tecno-científicos, como las posibilidades de tener un planeta sustentable para las generaciones futuras. En este sentido, todos los esfuerzos que se hacen por demostrar las limitaciones de la ciencias chocan contra ese imaginario que la racionalidad científica es la única que puede entregar la solución. Pero esto no es así, la crisis medioambiental y los profundos desafíos de la ecología obligan a repensar las ciencias en un nuevo proyecto de una racionalidad instrumental. Como indica Leff se trata de una nueva racionalidad:

La construcción de una racionalidad ambiental es un proceso político y social que pasa por la confrontación y concertación de intereses opuestos, por la reorientación de tendencias (dinámica poblacional, racionalidad del crecimiento económico, patrones tecnológicos y barreras institucionales); por la creación de nuevas formas de organización productiva, la innovación de nuevos métodos de investigación, y la producción de nuevos conceptos y conocimientos (LEFF, 1994, p. 20).

Esto tiene serias consecuencias no solo para las ciencias exactas sino también para las ciencias aplicadas, y sobre todo para las ciencias sociales. Nunca antes surgieron tensiones y contradicciones entre las elites gubernamentales y empresariales y los movimientos indígenas y ecológicos; hemos tomado como sociedades una mayor conciencia de los riesgos y límites que son parte de una sociedad del conocimiento y de su accionar tecnológico. Esto conlleva un nuevo modo de criticar las ciencias sociales en vistas a profundizar los procesos sociales y políticos del medio ambiente:

La rigidez y el apriorismo de la ciencia social, impiden captar la causalidad sociológica de los problemas ambientales y los procesos de cambio social que están en germen en la ética y en los objetivos del movimiento ambientalista, obstaculizando una praxeología que oriente 
el movimiento ambiental hacia la construcción de una racionalidad social (LEFF, 1994, p. 22-23).

Sería importante profundizar estos puntos de contacto entre las preocupaciones medioambientales y de la sustentabilidad planetaria con la problemática levinasiana descrita en la primera parte, en particular con las exigencias de un cuestionamiento del conocimiento formalista que se ha presentado bajo la forma de la única objetividad y utilidad que pretende la tecnociencia. Se ha cuestionado mucho en estas últimas décadas el punto de vista 'objetivista' que presupone que la realidad misma del mundo es sólo asequible mediante determinadas operaciones intelectuales que condicionan el abordaje teórico-práctico de la experiencia natural. Empero la principal dificultad es que este tipo de lenguaje objetivista ha sido traspasado a-críticamente a todos los campos del saber y que aparece en los Medios de Comunicación Social donde la opinión pública termina oponiéndose a todo lo que es subjetivo. Esta es otra de las dicotomías actuales que no ayudan a profundizar la problemática del saber reconstruido de cara a los desafíos de una eco-ética que asume las grandes tensiones que tenemos respecto de nuestros proyectos hegemónicos de desarrollo y las dificultades para dialogar con otras formas de saber y vivir en el mundo.

El interés de esta crítica radical del objetivismo del neopositivista radica no solo en la 'ingenuidad' gnoseológica de aplicar sobre la vida natural y los territorios los mismos parámetros formalistas, que no han surgido más que desde una subjetividad formal, sino que tienen que ver con la violencia de prácticas de dominación. Una ética del medio ambiente no es aplicable desde estos criterios no solo porque no se pueden justificar en términos absolutos respecto de ningún otro ámbito cognoscitivo de lo real, sino de que su única legitimidad proviene del ámbito de lo operatorio, es decir, de una cierta capacidad que permite actuar sobre la realidad. Se reconoce que es justamente ese ámbito de lo operatorio que permite el fuerte nexo entre la ciencia y la tecnología, y es en este ámbito donde se encuentra la relevancia de afirmar una ética de la responsabilidad.

Sobre la misma base de los análisis de Levinas queda en evidencia los criterios ideológicos que han cubierto las relaciones humanas y que tienen supuestos ético-políticos para intervenir en los territorios. En efecto, lo que se ha manifestado con el aparición del otro y de su rostro, es que intervención del modelo tecnocientífico no se basa en una perspectiva de la reciprocidad. En las ideas predominantes hoy en día, lo sucedido con esa lógica de intervención releva solamente de los imperativos fácticos, y no se destacan en primera instancia los elementos valorativos. En este sentido, los proyectos gubernamentales y empresariales que explicitan una responsabilidad social, en la mayor parte de los casos, es una cubierta ética que recubre la lógica de lo Mismo, y no permite afirmar el valor de la Otredad. El conocimiento de la naturaleza ha ido quedando al descubierto cada vez más, como lo considera el pensamiento crítico, que el predominio que asume la ciencia y tecnología en estas últimas décadas no están dadas por la aplicación del orden operatorio, sino por aspectos que provienen en muchos casos externamente a la ciencia y la técnica, y que aluden a la utilidad y al pragmatismo. Es decir no son las razones intracientíficas, las que llevan a afirmar la tesis de los conocimientos objetivos, sino un tipo de argumentación que permite "obligar" al otro como diría H. Maturana. En contraposición la preocupación por la vida práctica y por el cuidado de la naturaleza aparecen derivados de los conocimientos subjetivos en sociedades modernas que no aceptan cientifizarse. Basta simplemente ver como se usan los resultados de los estudios de impactos ambientes para observar las implicancias económicas, políticas y sociales de un determinado uso de la ciencia.

La crítica de la racionalidad científica recibe un punto de convergencia con el pensar intercultural que cuestiona su carácter hegemónico donde el modo concreto de abrirse al mundo del otro es parte de un conocimiento ligado al poder, que olvidamos con mucha frecuencia en la evaluación de los grandes proyectos de inversión. La cuestión desde esta perspectiva intercultural es mostrar que asumir el cuestionamiento del otro obliga a resituar el saber del otro, generalmente desechado. Se trata de este modo, no solo de un conflicto entre el monismo o el pluralismo cultural, sino de mostrar que una nueva mirada intercultural obliga a repensar el modo de intersección entre los diferentes segmentos de mundo de vida y entre diferentes mundos de vida; el enfoque intercultural para entender la diversidad cultural se construye ni negándola, ni haciendo de ella la causa de las dificultades que tenemos para visualizar el sentido de vivir juntos. El camino del entre-culturas, no recurre tampoco a un tercer término, desde donde se busca definir lo que requiere definir la intersección misma, se trata más bien de demostrar las dificultades inherentes de dicha comprensión de lo humano, donde es preciso reconocer que hay zonas de las otras culturas que nos quedan desconocidas para siempre, y otras que son posibles de explorar en conjunto con otros, donde el camino del encuentro 
verdadero con otros hombres y mujeres de otras culturas supone permanentemente el diálogo de saberes que emerge en la interacción común. Nos parece que haciendo este largo desvío por la filosofía actual se puede encontrar una adecuada comprensión del problema de una sociedad del conocimiento entendida a partir de los contextos culturales. En este plano, aunque hoy tomamos conciencia de las enormes posibilidades de este entrecruzamiento y también de los riesgos y de las limitaciones de la aventura tecno-científica, no somos aún capaces de reconocer el valor de la mirada de las comunidades humanas del territorio, y un caso particularmente significativo es el de los pueblos indígenas, donde en muchos casos sus saberes quedan obliterados. Terminemos con unas ideas generales acerca de una nueva reformulación de las ciencias que se adecuen a las nuevas perspectivas y problemas del pensamiento ambiental.

En síntesis, tal como lo indican las apreciaciones de Leff y Kerber, el pensamiento ambiental requiere repensar de un modo mucho más radical la crítica de la racionalidad moderna, y elaborar una nueva racionalidad ambiental que implica entender la complejidad en todo su conjunto: la interdependencia de las crisis; la vinculación de la crisis ambiental con el modelo de desarrollo; la importancia de la consideración ética de la cuestión; la relevancia de la praxis; la recuperación de la dimensión utópica; y la referencia a los saberes y a los estilos de comunión indígenas.

Casi todas las reflexiones generales expuestas derivadas del pensar levinasiano al pensamiento ambiental latinoamericano tienen por principal objetivo precavernos de aquellos estereotipos y caricaturas que han rodeado tanto estos temas vinculados a la ciencia y a la técnica en nuestras instituciones gubernamentales y académicas, como a captar la relevancia de los saberes culturales acerca de los territorios y la necesidad de repensar una nueva epistemología de los problemas ambientales. No es poco frecuente encontrar aún en muchos estamentos académicos de los países latinoamericanos donde predomina culturalmente un cierto cientificismo optimista, algunos que abogan por un cientifismo y/o por una defensa de la tecnociencia como camino para el desarrollo de nuestros países, que no se condice de ningún modo con los análisis críticos ya expuestos más arriba, y al mismo tiempo, encontramos a veces, en algunos colegas que están muy influenciados por el nihilismo donde ellas aparecen como figuras moribundas de una cultura racionalista moderna sin entregar elementos o criterios para reconstruir nuevas prácticas ecoéticas. A mi parecer, este modo cientificista o anticientificista no responde aún a toda la complejidad ética y medioambiental de la tecnociencia, y quedan solamente como formas culturales de intelectuales $\mathrm{y} / \mathrm{p}$ académicos que resisten comprender la dinámica y el movimiento de la racionalidad contextualizada. Por ello para concluir haremos algunas referencias a esta nueva racionalidad que debiera inspirar el pensamiento ambiental.

\section{Conclusiones}

Desde mediados del siglo XX, la filosofía europea queda en evidencia que el destino del objetivismo es consagrar la ruina de la propia ciencia: ésta es el sentido de la obra póstuma de Husserl y que ha sido proseguida en términos radicales por Levinas. Como ya indicamos no se trata hoy de concentrarse solamente en la crítica de la forma tecnocientífica del saber, sino claramente en un cuestionamiento ético de los enclaves socio-políticos y económicos de las hegemónicas sociedades occidentales que reiteran el mismo decurso de un proyecto moderno de intervención que no admite la alteridad y consagra la violencia. De cierto modo, existe necesariamente un lazo indesmentible entre la ciencia y la ideología que traspasa todas las sociedades del conocimiento y las prácticas de homogenización que lleva adelante el modelo actual de desarrollo y su modo unilateral de asumir los territorios desconociendo el modo de los sujetos que los habitan.

Esta visión de una ética que se abre a la interpelación del otro, no tiene el sentido de una ética definida en términos funcionales con el actual modelo de desarrollo. Se trata más bien de una ética de la responsabilidad de aquéllos que no tienen el poder y que son frágiles y vulnerables frente a una concepción totalizadora de lo tecnológico. Hoy la ecoética vuelve problemática este modo de entender tal reducción de la racionalidad. Como nos lo dijo hace años J. Ladrière:

Todas las peripecias que marcan la evolución del pensamiento contemporáneo hacen manifiesto cada vez más un quiebre que, desde el punto de vista de la reflexión filosófica aparece como una crisis de la razón. Una cierta configuración que razón se había dado se encuentra sordamente minada por la expansión de las grandes fuerzas que dan a la modernidad su figura particular: la ciencia, la técnica, las formas contemporáneas del estado y de la política (LADRIÉRE, 1974, p. 8-9). 
Esta ligazón compleja ES la que se vuelve problemática hoy, porque aparte de estar asentada a una visión reductiva e ideológica de lo real, el conocimiento científico-tecnológico y sus asideros ético-políticos funcionales, terminan justificando la violencia acerca de los otros y negando, con cierta frecuencia tanto la legitimidad y la pertinencia como el sentido y la validez de los diversos "saberes locales" acerca de su entorno ecológico, que son, inherentes a las culturas humanas. En otras palabras, hay que reconocer que el mundo natural tal como aparece en las diversas culturas humanas no se puede desvincular nunca del mundo de la vida. Depende del modo como se asuman los saberes que aparecen en todas las culturas que conocemos hoy para poder comprender el modo de entender la responsabilidad que se tiene con su nicho ecológico, y de donde probablemente pende la aventura humana en el planeta.

Son estas dicotomías surgidas de dichas sociedades formadas en el ideario científico las que han pretendido, a partir de una determinada filosofía de la historia definir un estadio ideal de la ciencia, imponer un criterio de la racionalidad, que hoy no parece justificado filosóficamente ni lógica ni epistémica ni históricamente. En verdad, la fuerza del modelo actual de desarrollo se basa simplemente en razones fácticas como indicaba Husserl, ésta es la verdadera crisis de las "ciencias europeas" que es entonces la crisis del saber mismo, de los modos como dichas ciencias entendieron y se explicaron, y continúan entendiendo y explicando a las denominadas sociedades "menos científicas". Salir de este atolladero histórico implica revertir ese proceso de homogeneización y abrirse a la exterioridad de los otros, de los otros saberes y de las otras prácticas.

Empero, muchas de estas afirmaciones críticas y cuestionadoras de la hegemonía de la ciencia actual son frecuentemente mal comprendidas, porque se mantiene, con cierta frecuencia, un parámetro equívoco donde el cuestionamiento de la ciencia instrumental, o la crítica a su pretensión pragmática y objetivizadora, exigiría necesariamente aceptar una tesis que menospreciaría la ciencia y sus verdaderos aportes. Como argumento complementario, habría que responder a la objeción que tal crítica querría introducir subrepticiamente el subjetivismo en el conocimiento acerca del mundo natural y del mundo histórico.
Me parece que es preciso decirlo con mucha más claridad y fuerza, que el verdadero problema de la racionalidad es que no somos capaces de cuestionar la operación epistémica del Cogito, y no en restringirse únicamente a cuestionar sus estereotipos. Como señala acertadamente Leff: "La construcción de una racionalidad ambiental implica transformaciones de los conceptos y métodos de diversas ciencias y campos disciplinarios del saber, en los sistemas de valores y las creencias de diversos grupos sociales" (LEFF, 1994, p. 51). Empero, esta crisis de la razón no implica de ninguna forma ni la muerte ni la disolución de la razón, sino que puede significar un nuevo nacimiento, y quizás como sostiene Ladrière, es preciso la paciencia y el sufrimiento de este logos para que se revele mejor sus nuevas articulaciones y es desde aquí donde surge las potencialidades utópicas. Como lo dice Leff:

La construcción de una racionalidad instrumental implica la realización de una utopía. Sin embargo, ésta no es la materialización de principios ideales abstractos, sino que emerge como un proyecto social de respuesta a otra racionalidad que ha tenido su periodo histórico de construcción, de legitimación, de institucionalización y de tecnologización (LEFF, 1994, p. 46).

En esto proseguimos la tesis de Levinas y Ladriére, quien retomando la propuesta crítica de Husserl al racionalismo, le permite resituar un concepto más amplio y mucho complejo de la racionalidad que está vinculada con nuestra tesis de la racionalidad contextual y práctica: "La razón, lo racional, es en la experiencia misma, lo que hace que ella esté abierta para una autoexplicitación sin límites" (LADRIÉRE, 1974, p. 29-30). En este sentido, la idea ladrièriana de razón es, en esta perspectiva no del ocultamiento de una crisis, sino también de una afirmación acerca de la esperanza de la razón, es decir de la esperanza del sentido, de la verdad y de la moralidad. En este sentido, la cuestión relevante se vuelve definir cuál es el proceso que sigue la razón en su propia dinámica teleológica de un sentido que apunta al esjaton. 


\section{Bibliografía}

CRAGNOLINI, M. Alteridad/otro. In: Diccionario Latinoamericano de Bioética. Bogotá: UNESCO. Ediciones UNColombia, p. 22-25, 2008.

CINTRA, B. E. L. Levinas e a Filosofia da Libertação de E. Dussel. In: SOUSA, Timm de et al. Alteridade e ética. Porto Alegre: Edipucrs, 2008, p. 100-116.

FORNET-BETANCOURT, R. Interculturalidad y Filosofía en América Latina. Concordia Band 36: Aachen, 2003.

. La interculturalidad a prueba. Concordia Band 43: Aachen, 2006.

GARCIA, P. H. La representación del Otro. Investigaciones fenomenológicas, v. 7, p. 219-231, 2010.

GONZALEZ, G. La filosofía de la liberación de E. Dussel. En: A Parte Rei. Revista de Filosofia, p. 49, 2007.

KERBER, G. Ecología. En: SALAS ASTRAIN Ricardo (Org,): Pensamiento Crítico Latinoamericano. Santiago: Ediciones UCSH, 2005, 3 tomos.

KUSCH, R. Esbozo de una antropología filosófica americana. En: KUSCH Rodolfo : Obras Completas. Rosario: Editorial Fundación Ross, 1990, Tomo III.

LADRIÉRE, J. Vie sociale et destiné. Namur: Éd. Duculot, 1974.

L'Éthique dans l'univers de la rationalité. Namur: Fides-Artel, 1997 (trad. Castellana, Tucuman, Ediciones U. Norte, 2006).

LEFF, E. (Comp.). Ciencias sociales y formación ambiental. Barcelona: Gedisa, 1994.

LEVINAS, E. Totalidad e infinito. Salamanca: Sígueme, 1977.

Entre nosotros. Ensayos para pensar en otro. Valencia: Pretextos, 2001.

MEINHARDT, G. (Org.). Alteridade peregrina. Sao Leopoldo: Oikos-Nova Harmonia, 2008.
MIGNOLO, W. Historias locales/diseños globales. Colonialidad, conocimientos subalternos y pensamiento fronterizo. Madrid: Ediciones AKA, 2003.

MALIANDI, R. Cultura y conflicto. Buenos Aires: Editorial Biblos, 1984.

ROIG, A. A. Teoría y la crítica del pensamiento latinoamericano. Mexico: FCE, 1981.

SALAS, R. Ética intercultural. Santiago de Chile: Ediciones UCSH, 2003.

SALAS, R. Ética, políticas del reconocimiento y culturas indígenas. En: ALVAREZ David \& SALAS ASTRAIN Ricardo (Org..): Estudios Interculturales, Hermenéutica y Sujetos Históricos. Santiago: Ediciones UCSH, 2006.

. El problema de la experiencia humana en la filosofía intercultural. In: FORNET-BETANCOURT, R. (Hrs.). Menschenbilder Interkulturell. Culturen der Humanisierung und der Anerkennung, Aachen: Verlagsgruppe Mainz in Aachen, p. 276-297, 2008.

Saberes y sociedad del conocimiento. Una perspectiva intercultural de la ética y del medioambiente. En: El desafio del conocimiento para América Latina, Santiago, Ediciones IDEA, p. 285-301, 2010.

SAUERWALD, G. Reconocimiento y Liberación. Axel Honnett y el pensamiento latinoamericano. Berlin: Lit Verlag, 2008.

SCANNONE, J. C. La filosofia de la liberación, historia, características y vigencia actual. In: Teología y Vida, v. 50, n. 1-2, p. 59-73, 2009.

SIDEKUM, A. Alteridade e multiculturalismo. Ijuí: Ed. Inujui, 2003.

VARIOS AUTORES. Interculturalidad crítica y descolonización. La Paz: Instituto Internacional de Integración, 2009.

Recebido em fevereiro de 2011. Aceito em abril de 2011. Publicado em junho de 2011. 